\title{
Matches and Gaps in the Green Logistics market
}

Uni Martinsen and Maria Björklund

\section{Linköping University Post Print}

N.B.: When citing this work, cite the original article.

Original Publication:

Uni Martinsen and Maria Björklund, Matches and Gaps in the Green Logistics market, 2012, International Journal of Physical Distribution \& Logistics Management, (42), 6, 562-583. http://dx.doi.org/10.1108/09600031211250596

Copyright: Emerald

http://www.emeraldinsight.com/

Postprint available at: Linköping University Electronic Press http://urn.kb.se/resolve?urn=urn:nbn:se:liu:diva-68838 


\section{Matches and Gaps in the Green Logistics Market}

\section{Purpose}

The interface between Logistics Service Providers (LSPs) and shippers is an area that has received little attention in previous research and even less has been done when environmental issues are added to this interface. Nonetheless, the perception among researchers and the industry is that in many instances, supply and demand in this green interface does not coincide. The purpose of this paper is therefore to identify the matches and gaps between LSPs' green supply and the shippers' green demand.

\section{Design/methodology/approach}

This paper is based on a web-based survey sent out to Swedish LSPs and shippers. A gap analysis based on mean values and confidence intervals was conducted.

\section{Findings}

Findings indicate that the LSPs overachieve when it comes to green categories and also that they are aware of this situation. Shippers, on the other hand, are interestingly not aware of this and they seem satisfied with what they perceive is offered by LSPs.

\section{Research limitations/implications:}

Contrary to previous research, this study specifies matches and gaps in the green LSP-shipper interface. As the survey covers actors on the Swedish market, future research would benefit from similar analyses from other countries.

\section{Practical implications:}

The findings are of use for LSPs' understanding of shippers' environmental demand, and thereby enable them to adapt better to market demand. Similarly, shippers can use the findings to understand green supply and possibly change their demands accordingly.

\section{Originality/value}

This paper adds to the knowledge of the green LSP-shipper interface. Furthermore, it uses gap analysis, which appears to be something not previously done within environmental logistics research.

\section{Keywords}

Logistics service provider, shipper, interface, green logistics, gap analysis 


\section{Matches and Gaps in the Green Logistics Market}

\section{Introduction}

The management of interfaces is central in supply chain management (SCM) and logistics. An important part of SCM is coordination and collaboration with different partners such as suppliers, intermediaries, third party service providers and customers (CSCMP, 2010). Collaboration between parties in the supply chain is generally believed to decrease costs and increase efficiency as well as service. Moreover, the success of a firm is dependent on its managerial ability to integrate and coordinate the business relationships among the supply chain members (Lambert and Cooper, 2000). The supply chain linkage ought to be so tight that separate organizational units share the same purpose, with suppliers and customers helping each other to achieve mutually beneficial objectives (Bommer et al., 2001).

In the SCM literature, interfaces seldom include the logistics service provider (hereafter labelled the LSP). Instead, the most commonly discussed interfaces are those between the shippers and the receivers of goods (Skjoett-Larsen et al., 2003; Stefansson, 2006). One reason for this could be that logistics firms are the least integrated link in supply chains (Lemoine and Skjoett-Larsen, 2004), or, as noted by Fabbe-Costes et al. (2009), LSPs seem to be the forgotten actors of supply chain integration. Furthermore, LSPs are often merely seen as actors that support other members of the supply chain, providing resources, knowledge, utilities and assets (Spens and Bask, 2002). Several logistics related trends, such as the shift towards outsourcing and increased globalisation, increase the need for stronger relationships between LSPs and supply chains (Seth et al., 2006).

Most of the research conducted on LSPs applies either only to a shipper or to the perspective of an LSP, instead of a dyadic perspective. Literature in the context of service quality in supply chains also commonly considers only one directional view (Seth et al., 2006). Knemeyer and Murphy (2005) state that there is a need to simultaneously consider the perspectives of both the shipper and the LSP in order to decrease the risk of key perceptual differences (gaps) that can negatively influence the logistics service quality.

Shippers and LSPs face an emerging and considerable challenge as a result of the large negative impact transportation has on the natural environment and, as stated by for example the EEA (2007) and Roth and Kåberger (2002), the environmental performance of the transport sector is 
an increasing problem. Because of increased usage of freight transport it is not surprising that both shippers and LSPs are pressured by different stakeholders, such as governments and customers, to lower their environmental impact from transportation (McKinnon, 2003; McKinnon and Piecyk, 2009; Wolf and Seuring, 2010). This creates an opportunity for LSPs to be proactive and meet these demands by considering environmental issues in their business models and as a value adding service offer.

The correspondence between customer needs and the service offers is essential in order to succeed with the service concept (Edvardsson, 1997); however, that does not necessarily mean that supply and demand always match. For example, Wolf and Seuring (2010) found that the LSPs seem to be ahead of their customers when it comes to environmental issues, although they state this with caution and call for further research in this area.

With the aim of learning more about the interface between LSPs and shippers and how environmental issues are taken into account, the purpose of this paper is:

To develop and apply a tool for the identification of matches and gaps in the interface between the environmental demands of the shippers and the corresponding offers from the LSPS.

The offers and demands of green logistics are defined in this paper as considerations taken in respect of the natural environment in the supply or purchase of logistics services. We take a wide approach towards environmental concerns and include green categories such as the use of environmentally preferable technology, the use and spread of environmental knowledge, and the inclusion of environmental concerns in the logistics management.

There are many ways to label the actor responsible for the supply of logistics services. In this paper, the term logistics service providers (LSPs) is applied and, inspired by Fabbe-Costes et al. (2009) and Forslund (2010), includes actors such as carriers, forwarding agents and companies, transport(ation) companies, third party logistics providers/partners and logistics service companies/providers/suppliers.

This paper is divided into five main parts. After the introduction, a literature section on the "greening" of the LSP-shipper interface will be presented. This is followed by a section focussing on service gaps, in which a model is proposed and developed. Next, the survey study is 
explained, after which the findings from the application of the model are presented. The paper ends with conclusions and suggestions for future research.

\section{The LSP-shipper interface}

Wandel et al. (1992) describe the interface between shippers and LSPs in terms of a logistics market (see Figure 1). In this market, the need for material flows and demands for logistics services by shippers meet, and hopefully match, the LSPs' system for transport flow and supply of logistics services. Similarly, Sheffi (1986, p.2) describes the transportation market thus: "Interactions between carriers and shippers can be considered supply and demand actions in a freight transportation 'market'. In the transportation market, carriers 'supply' and shippers 'consume' transportation services." The efficiency in the match between supply and demand can be measured in terms of service quality.

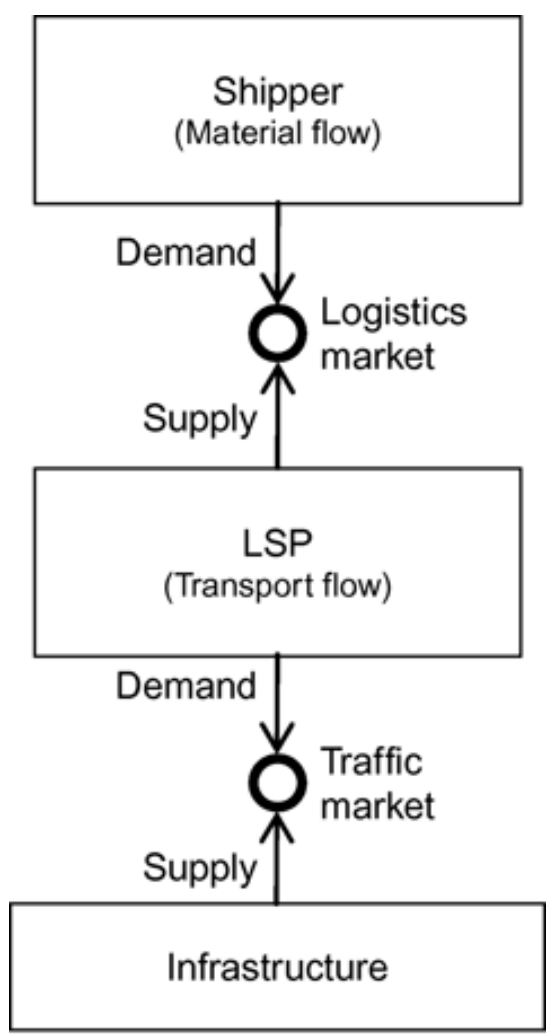

Source: Adapted from Wandel et al. (1992)

Figure 1The logistics market illustrated in a three-layer model 
The development of green logistics services is an active interface between the demand and supply sides, where both sides pressure and respond to each other (Martinsen and Huge-Brodin, 2010). In the following paragraphs, green supply and demand in the green logistics market are presented, after which environmental considerations in this market are discussed.

\section{The green supply}

According to Lin and Ho (2008), LSPs are willing to make their services more environmentally friendly and to react to customer demands. However, the degree of success with which the LSPs meet these new demands depends on their ability, attitude and knowledge about how to develop green services (Roth and Kåberger, 2002). Some researchers state that suppliers have a responsibility to satisfy customer demand, and that providers need to integrate customers' requirements and expectations in the development of services (Kumar and Kumar, 2004). The product and service development literature also indicates the importance of early customer involvement in the development of sustainable services, and point to the importance for shippers of understanding customers' demands (Coley and Lemon, 2009; Maxwell et al., 2006; Pujari et al., 2003). Bommer et al. (2001) even state that activities not driven by customer requirements ought to be eliminated, since these do not create value for customers. LSPs have begun to take action by offering different kinds of green services, such as DHL's two offerings "Go green" and calculations of environmental impact. The environmental aspect of an offer is also singled out as an important differentiation strategy for intermodal transportation (Jensen, 2007) and one which can be used in the marketing of freight transportation (Lammgård, 2007).

\section{The green demand}

Traditionally, environmental issues have seldom been included in the literature of transport purchasing (Bowersox and Closs, 1996; Coyle et al., 2000), despite the fact that mode and carrier selection are singled out as important logistics decisions that influence the environment (Wu and Dunn, 1995). Recent studies indicate that shippers' demands for environmentally responsible transportations are rising (de Haas and Kronborg Jensen, 2010; Facanha and Horvath, 2005; Wolf and Seuring, 2010), yet despite this, there is still limited evidence of environmental issues constituting buying criteria for LSP services (Wolf and Seuring, 2010). Many shippers believe 
that they are able to influence the environmental status of logistics services, and one way they try to do this is through investigations of the environmental status of the providers (Björklund, 2005). For example, Wolf \& Seuring's (2010) research finds that the number of questionnaires received by LSPs from their customers on the subject of their environmental performance is increasing.

\section{Green categories on the green logistics market}

Details about environmental supply by LSPs and the green demands of shippers are difficult to find in current literature (Martinsen and Huge-Brodin, 2010). Although Wolf and Seuring (2010) study how the environment is taken into account when logistical services are purchased, they do not go into much detail about specific issues. Instead, terms like "most environmentally advanced" and "all relevant environmental aspects" are used. However, there are other studies that have dealt with how environmental issues are taken into account in the purchase of transport services. Björklund (2005) showed that Swedish shippers commonly investigate technical solutions (age, engines, modes applied and type of fuel used) and LSPs' environmental routines (management system and environmental education). The green categories that Enarsson (1998) suggests are important to consider when purchasing transportation services include: the amount of return loads, choice of transportation mode, and load optimising; whereas Lundgren (2001) describes the following as factors that can be included in demand: type of fuel, use of IT, cost efficient driving, load factors, maintenance of modes, type of mode, age, and engine type. One of the most commonly applied environmental demands in Sweden is the ISO 14001 certificate (Björklund, 2005).

An attempt to identify green categories in LSPs' offers was made recently by Martinsen and Huge-Brodin (2010). The identification was based on general green logistics literature (e.g. Aronsson and Huge-Brodin, 2006; McKinnon, 2008; Wu and Dunn, 1995) as well as a survey and a scan of web homepages. The study takes into account the categories mentioned above, but takes a more holistic view of the offer. The green categories found in the study are presented in Table 1 below.

Table 1 - Green categories and examples.

Green category $\quad$ Examples




\begin{tabular}{|ll|}
\hline Fuels & $\begin{array}{l}\text { Bio fuels and renewable energy. If fossil fuels are offered or demanded, } \\
\text { limitations can include type of environmental class. }\end{array}$ \\
\hline Vehicle technologies & Modern vehicles that cause less emissions; Replace fleets more often. \\
\hline Modal choice & Shift from air to ocean, from road to rail; Intermodal solutions. \\
\hline Behavioural aspects & Eco driving; Driving behaviour with a focus on a decrease of fuel consumption. \\
\hline Logistics system design & $\begin{array}{l}\text { More direct transports; Continuous improvement of distribution network; } \\
\text { decrease average handling factor and average length of haul. }\end{array}$ \\
\hline Transport management & Well planned routes; High fill-rates. \\
\hline Choice of partners & $\begin{array}{l}\text { Cooperation with customers to help them reach their own environmental targets; } \\
\text { Choosing environmentally conscious transport providers }\end{array}$ \\
\hline $\begin{array}{l}\text { Environmental management } \\
\text { system }\end{array}$ & $\begin{array}{l}\text { ISO 14 001, EMAS } \\
\text { Emissions data and Energy } \\
\text { data }\end{array}$ \\
\hline
\end{tabular}

\section{Gaps and gap models}

A key issue in customer service is to understand and meet the customer's needs and requirements (Bommer et al., 2001). The service literature shows that customers can have different expectations of a service than those of their suppliers; a gap arises when parties do not share the same perception of the service (Hakatie and Ryynänen, 2007). Researchers who have studied these potential gaps have been inspired by the terminology of "service quality" (Parasuraman et al., 1985) in studies of the differences in service expectations and services received by customers (Seth et al., 2006). The rationale behind the development of "service quality" as described by Parasuraman et al. (1985) is that service quality, as opposed to product quality, is more difficult for consumers to understand, and is also more difficult to measure. The reason for this is basically four service characteristics that separate services from products: intangibility, heterogeneity, inseparability and perishability (see for example Parasuraman et al., 1985; Shostack, 1977; Zeithaml et al., 1985). Successful service providers can be described as "those who are able to zero the gap between required services and the services delivered" (Kumar and Kumar, 2004, p. 316). Neither a positive nor negative gap is recommended; a negative gap implies that customer demands are not met, while large positive gaps indicate that the service 
level is too high, resulting in "service overkill" (Lings and Brooks, 1998), which can imply a waste of resources that could be better spent on something else (Large and König, 2009).

The gap model introduced by Parasuraman et al. (1985) conceptualizes service quality as a comparison between customers' and suppliers' current expectations and perceptions. Thus, the gap model strives to measure the perception of the actual performance, not best practice (Mukherjee and Nath, 2005). The model developed by Parasuraman et al. (1985) summarizes key insights about the concept of service quality and the factors affecting it. One important part of this model is the five gaps identified (see Figure 2):

1. The consumer expectation-marketers' management perception gap.

2. The marketer internal gap: management perception- service quality specification gap.

3. The marketer internal gap: service quality specifications-service delivery gap.

4. The marketer internal gap: service delivery-external communication gap.

5. The consumer internal gap: expected service-perceived service gap.

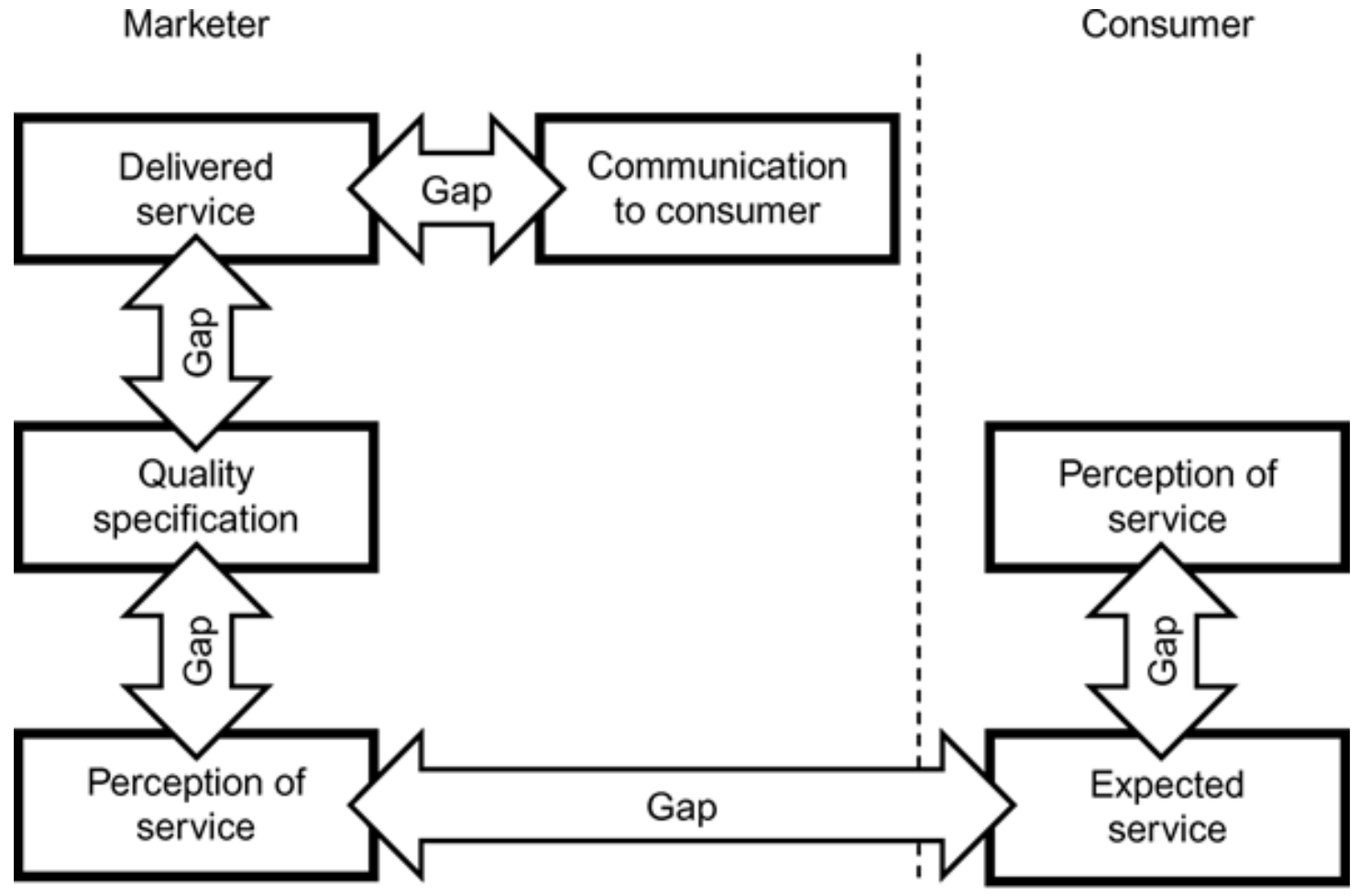

Source: Adapted from Parasuraman et al. (1985)

Figure 2 Service quality gap model 
The gap model enables researchers and practitioners to contrast the views of customers and suppliers. It has been described as a predominant model in the customer satisfaction literature, and is a well-known and widely used approach to determine whether or not consumer needs have been satisfied (Lin and Ho, 2008; Mukherjee and Nath, 2005). Moreover, the gap model can facilitate insight into customer demands and can therefore be used as a well-structured guide for suppliers striving to adapt their offers to these demands (Skålén and Fougère, 2007).

\section{Gap models in logistics}

The gap model is often adjusted to the specific situation of different service industries (Skålén and Fougère, 2007). The quality of logistics service was in early research described by performance gaps measured in terms of a company's ability to distribute a product in conformance with customer requirements and standards (Stock and Lambert, 1992). External audits were suggested as a means to understand customer expectations, whereas internal audits have been described as a means to assess the level of customer service provided (Stering and Lambert 1989, in Bommer et al., 2001). Since then, the gap model has been applied by several researchers in the logistics field. Forslund (2006) used a gap model to identify potential service quality gaps between large manufacturing companies and their suppliers. Seth et al. (2006) used a gap model to analyse service quality gaps at various interfaces between LSPs and other actors in supply chains and suggested that gaps may exist between an LSP and a manufacturer. Service quality gaps between the shipper and carrier were also identified in the study by Hopkins et al. (1993), who suggested that modern equipment is overrated by the carriers and is of less interest

to the shipper. Giannakis (2007) developed an analytical gap model that takes both soft and hard dimensions of supplier relationships into account, and aims to assess the performance of supplier relationships. This conceptual gap model consists of six gaps between the differences in perceptions of the performance in the relationship (see illustration in Figure 3). Five more gaps evolve when the perception of the nature of the relationship is taken into consideration. 


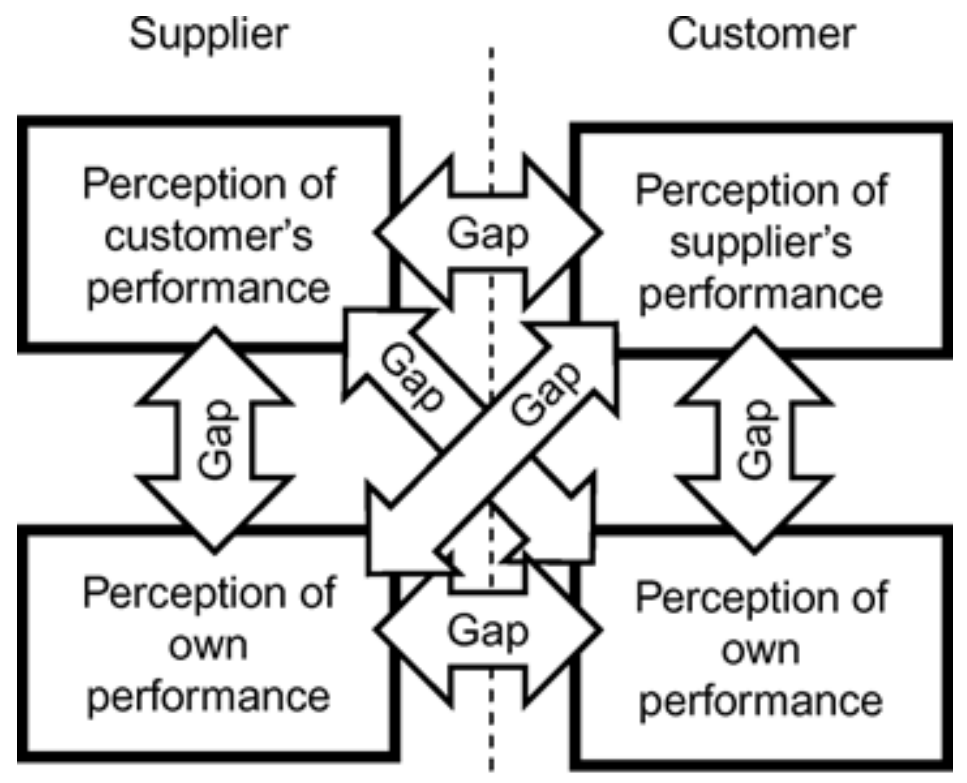

Source: Adapted from Giannakis (2007)

Figure 3 Relationship gap model

\section{Green gap model}

Examples of service quality categories that Parasuraman et al. (1985) include in their gap analyses are competence, communication and tangibles (i.e. physical evidence of the service). However, these service quality categories are not adapted for the measurement of sustainable services. In the development of sustainable services, there is a call for a broader consideration of customer satisfaction and not merely a focus on traditional service elements such as price, time, quality and functionality (Chen, 2001; Pujari et al., 2003). One of the strengths of the gap model is that new categories of service offers can be added easily. Moreover, the study by Giannakis (2007) suggests that it is possible to apply gap analyses to new categories of service quality, such as relationships. However, there are often problems related to how to describe and define expectations and perceptions when services not previously experienced are applied to the model (Mukherjee and Nath, 2005).

Despite the fact that numerous authors have developed and tested service quality models for different applications, no agreement on the exact categories of service quality exists. However, based on an extensive literature review, Seth et al. (2006) draw the conclusion that there seems to be a general agreement on the acceptability of a gap model for a variety of service quality 
categories. Despite some discussions in the literature about the categories of service, the gap model is well documented and the strengths of the gap model have been extensively explored in many service-industry studies.

In the development of a green gap model that can describe the green LSP-shipper interface, inspiration was, to some extent, gained from the original gap-model of Parasuraman et al. (1985), but to an even larger extent from the perception gap model by Giannakis (2007). Our first dimension regards the actors involved. Two actors can be identified in each of the two models: Parasuraman et al. describe the gaps between consumer and marketer, and Giannakis' model illustrates the gap between suppliers and customers. Our model illustrates the buyer and supplier side which, in our context of the logistics service interface, we have labelled shipper and LSP. Our second dimension regards the distinction made by e.g. Parasuraman et al. who state that service quality is a comparison between expectations and demands. Giannakis uses a similar comparison between how the involved actors perceive their own performance and how they perceive the performance of the other actor. In our model we make a similar distinction and take the following into account: how the LSPs' state their offers; how the LSPs perceive the shippers' demand; how the shippers' state their demands; and finally how the shippers perceive the LSPs' offers. Based on this, five gaps emerge with regard to the green LSP-shipper interface. Three of these gaps are external, meaning that they measure a gap between LSPs and shipper, and two are internal, meaning that they measure a gap perceived by one of the two actors. The suggested model includes the following gaps (see also Figure 4):

- Gap 1: External gap between LSPs' stated offer and shippers’ stated demands.

- Gap 2: Internal gap between LSPs' stated offer and their perception of shippers' demands.

- Gap 3: External gap between LSPs' stated offer and shippers' perception of the offer.

- Gap 4: External gap between shippers' stated demands and LSPs' perception of those demands.

- Gap 5: Internal gap between shippers' stated demands and their perception of the offer. 


\begin{tabular}{|l|l|}
\hline LSP-questions & Shipper-questions \\
\hline $\begin{array}{l}\text { A: To what extent do you include any of the } \\
\text { following categories in your green offer? }\end{array}$ & $\begin{array}{l}\text { B: To what extent are the following } \\
\text { categories included in your green demand? }\end{array}$ \\
\hline $\begin{array}{l}\text { C: To what extent do you perceive that the } \\
\text { shippers include any of the following } \\
\text { categories in their green demand? }\end{array}$ & $\begin{array}{l}\text { D: To what extent do you perceive that the } \\
\text { LSPs include any of the following categories } \\
\text { in their green offer? }\end{array}$ \\
\hline
\end{tabular}
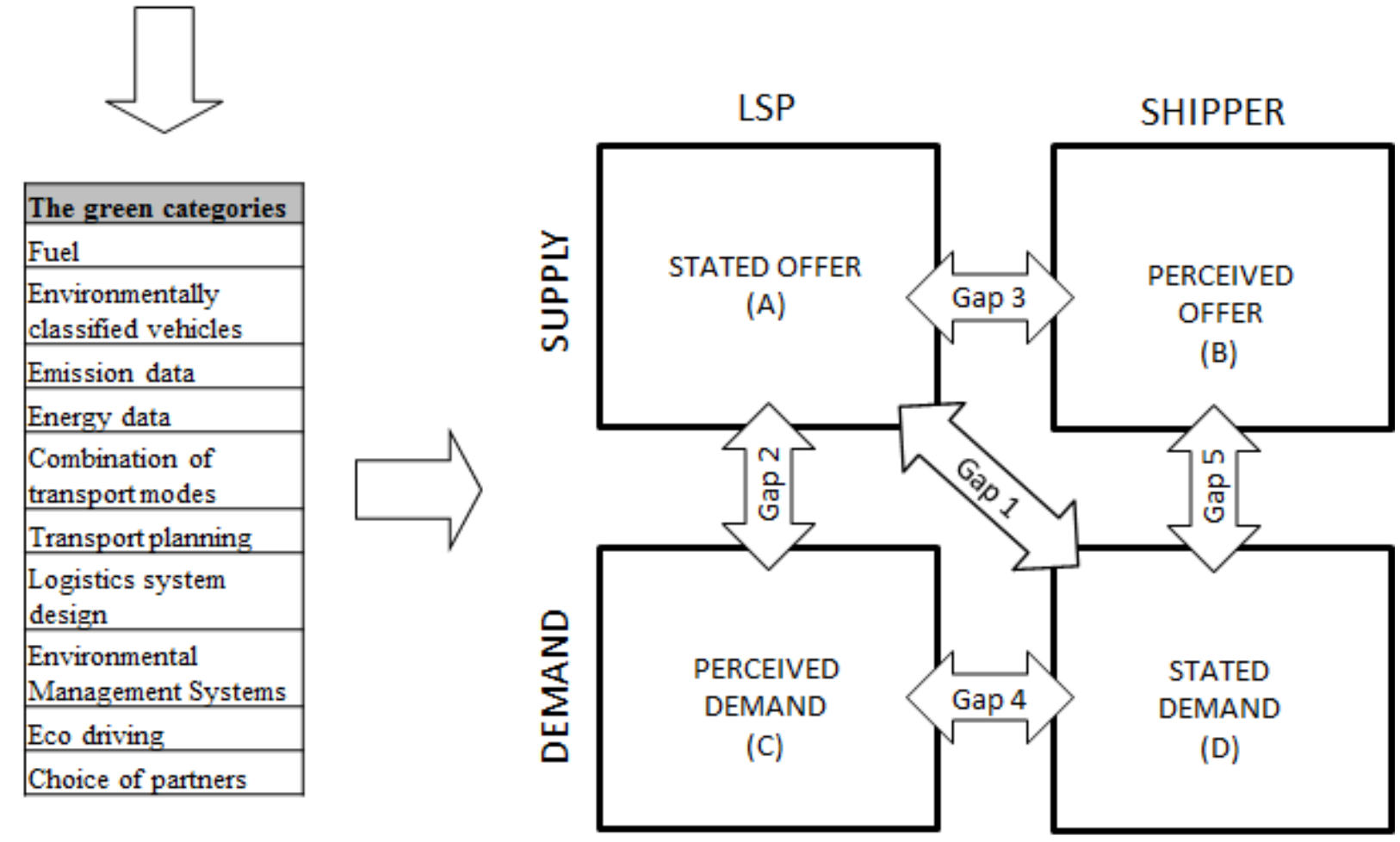

Figure 4 The green logistics gap model

\section{The survey study}

The gap model was used to structure questions on a web based survey sent out to both LSPs and shippers. Although part of a much larger research project, for the purpose of this article, five specific questions were included in the survey. The first question was a nominal scale question to identify if the respondent was an LSP or shipper. The following four questions addressed one box each of those illustrated in Figure 4. Two of the questions were answered by the LSP's: the LSPs' stated offer (A in Figure 4) and their perception of the shippers' demands (C). Two questions were answered by the shippers: the shippers' stated demands (B) and their perception of the LSP's offer (D). All four questions had the same answer alternatives covering ten green categories that share a number of similarities with those presented by Martinsen and Huge- 
Brodin (2010). The respondents answered according to a five-point Likert scale ranging from (1) "Totally disagree" to (5) "Fully agree" in the analysis of the survey. Respondents also had the option of answering "Do not know".

\section{Data collection}

Two different groups of respondents were targeted: logistics service providers and shippers. The survey was sent to members of two interest organisations, one of which represents LSPs (Swedish transport interest group - Transportgruppen) and the other representing shippers (Swedish purchasing network - SILF). We did not focus on shippers from any particular sector or company size; all respondents had the common determiner that they purchased logistics services. The LSPs' group of interest is much smaller compared to that of the shippers'. Of the 114 LSPs to whom we personally e-mailed the survey, eight were returned, mainly because the addresses were no longer employed by the companies. As for shippers, the survey was emailed to 1612 potential respondents; unfortunately, at least 537 of the e-mailed surveys were caught in spam filters and thus never reached their potential respondents. In total, the survey was answered by 55 LSPs and 103 shippers, of which 46 LSPs and 50 shippers addressed the four questions of relevance for the gap analysis in this paper. The number of relevant responses was very similar between the two groups of respondents. The efficient response rate for the questions of interest in this paper was $8.1 \%$ in total (4.7\% for the shippers and $43.4 \%$ for the LSPs).

\section{Data analysis}

The gap analysis was based primarily on the mean values of the answers from the respondents, corresponding with previous research that has used gap models (see e.g. Hopkins et al., 1993; Large and König, 2009). A more detailed study of the mean values was enabled by the use of confidence intervals, for which a confidence level of $95 \%$ was considered reasonable in accordance with, for example, Djurfeldt et al. (2010) and Hopkins et al. (1993). The analysis of the survey was carried out with SPSS 17.0.

\section{Trustworthiness}

Before the survey was distributed to potential respondents it was pre-tested for content validity and reliability on a group of LSPs and shippers. The test group was asked to report on any discovered difficulty or vagueness, and after this process minor adjustments to the survey were 
made. Despite this precaution, two minor errors were made when two out of the ten categories for question $\mathrm{C}$ were phrased. Thus, there is a small risk that respondents misinterpreted these categories and therefore they have been removed from the data set of Gap 2 and Gap 4 where question $\mathrm{C}$ is involved.

Non-response bias is of importance for the trustworthiness of the survey. The higher the response rate, the lower the risk of non-response bias (Lambert and Harrington, 1990). This makes this reliability test even more important for the shipper respondent group, since their response rate was only $4.7 \%$, as compared to the LSPs response rate of $43.4 \%$. In an attempt to increase the response rate, a reminder was sent out to all potential respondents. In addition, a comparison between early and late respondents was conducted, since similar responses decrease the risk of non-response bias (Armstrong and Overton, 1977). T-tests of the four survey questions showed no significant differences between early and late responses when a significance level of 0.05 was used, thus indicating that no major differences between the two respondent groups exist.

\section{Findings}

In this section the five studied gaps presented in figure 4 are discussed one by one.

\section{Gap 1}

Gap 1 represents the external gap between LSPs' stated supply and shippers' stated demand. As can be seen in Table 2, the shippers' green demands are lower in all categories than those supplied by the LSPs. The gaps found vary between 0.29 and 1.10 . The biggest gaps are found in transport planning, logistics system design, modal choice, and energy data, all of which have gaps slightly above or below 1.0. These results are strengthened by the confidence intervals shown in Figure A1 (Appendix A), where none of the confidence intervals for the two relevant questions overlap in the four largest gaps. The smallest gap is found for environmentally classified vehicles, closely followed by fuel. As can be expected, the confidence intervals for the LSPs and shippers overlap to some extent for both these questions, since the gaps are relatively small. However, as Figure A1 shows, the responses for the LSPs and the shippers have approximately the same spread for each category.

Table 2 - Mean values representing Gap 1 


\begin{tabular}{rccc}
\hline Fuel & $\begin{array}{c}\text { LSPs' stated } \\
\text { offer (A) }\end{array}$ & $\begin{array}{c}\text { Shippers' stated } \\
\text { demand (B) }\end{array}$ & $\begin{array}{c}\text { Gap 1 } \\
\text { Environmentally classified }\end{array}$ \\
vehicles & 4,12 & 3,50 & 0,29 \\
Emission data & 4,13 & 3,86 & 0,26 \\
Energy data & 4,03 & 3,30 & 0,83 \\
modes & 3,89 & 3,06 & 0,97 \\
\hline Combination of transport & 4,13 & 2,86 & 1,03 \\
Transport planning & 4,14 & 3,03 & 1,10 \\
\hline Logistics system design & 3,08 & 1,06 \\
Environmental & 3,88 & 3,50 & 0,38 \\
Management Systems & 3,75 & 3,23 & 0,52 \\
Eco driving & 3,77 & 3,05 & 0,72 \\
\hline Choice of partners & $1=$ Totally disagree $\rightarrow 5=$ Fully agree
\end{tabular}

\section{Gap 2}

Gap 2 represents the internal gap between LSPs' stated supply and their perception of shippers' demands. As can be seen in Table 3, all categories show a gap where the LSPs' stated offer scores higher than their perception of demand. Almost all categories present a gap bigger than 1.0. The smallest gap for a category is found for environmental management systems, but this is still a large gap compared to the differences in Gap 1. This category is also the only one where the confidence intervals overlap to some extent (see Figure A2, Appendix A). It also seems as though the spread in general is larger for LSPs' perception of demand than their stated offers.

Table 3 - Mean values representing Gap 2

$\begin{array}{rccc} & \begin{array}{c}\text { LSPs' stated } \\ \text { offer (A) }\end{array} & \begin{array}{c}\text { LSPs' perception of } \\ \text { demand (C) }\end{array} & \text { Gap 2 } \\ \text { Fuel } & 3,79 & 2,84 & 0,95 \\ \text { Emission data } & 4,13 & 3,00 & 1,13 \\ \text { Energy data } & 4,03 & 2,51 & 1,51 \\ \text { Transport planning } & 4,13 & 2,71 & 1,41 \\ \text { Logistics system design } & 4,14 & 3,02 & 1,12 \\ \text { Environmental } & & 3,21 & 0,68 \\ \text { Management Systems } & 3,88 & 2,67 & 1,08 \\ \text { Eco driving } & 3,75 & 2,72 & 1,05 \\ \text { Choice of partners } & 3,77 & \text { 1 } & \text { Totally disagree } \rightarrow 5=\text { Fully agree }\end{array}$




\section{Gap 3}

Gap 3 represents the external gap between LSPs' stated offer and the shippers' perception of the offer. As shown in Table 4, the findings from the survey suggest that the LSPs give their green offers a higher weight than do the shippers when asked how they perceive the LSPs' offers. The gaps for the green categories in the different actors' perception of the green offers vary between 0.19 and 1.09. The three smallest green-category gaps appear for environmentally classified vehicles, fuel and eco-driving, for which the shippers seem to agree with the LSPs' offer to a large extent. The largest category gap in the Gap 3 analysis appears for energy data, followed by emissions data. For these two categories, the confidence intervals for LSPs and shippers do not overlap (Appendix A, Figure A3). Moreover, for the three following large green category gaps (transport planning, combination of transport modes and logistics system design) the confidence intervals merely show small overlaps.

Table 4 - Mean values representing Gap 3

\begin{tabular}{|c|c|c|c|}
\hline & $\begin{array}{l}\text { LSPs' stated } \\
\text { offer (A) }\end{array}$ & $\begin{array}{c}\text { Shippers' perception of } \\
\text { offer (D) }\end{array}$ & Gap 3 \\
\hline Fuel & 3,79 & 3,59 & 0,20 \\
\hline \multicolumn{4}{|l|}{ Environmentally classified } \\
\hline vehicles & 4,12 & 3,93 & 0,19 \\
\hline Emission data & 4,13 & 3,22 & 0,91 \\
\hline Energy data & 4,03 & 2,94 & 1,09 \\
\hline \multicolumn{4}{|l|}{ Combination of transport } \\
\hline modes & 3,89 & 3,06 & 0,83 \\
\hline Transport planning & 4,13 & 3,29 & 0,84 \\
\hline Logistics system design & 4,14 & 3,42 & 0,73 \\
\hline \multicolumn{4}{|l|}{ Environmental } \\
\hline Management Systems & 3,88 & 3,47 & 0,41 \\
\hline Eco driving & 3,75 & 3,53 & 0,22 \\
\hline Choice of partners & 3,77 & 3,06 & 0,72 \\
\hline
\end{tabular}

\section{Gap 4}

Gap 4 is the external gap that illustrates the differences between shippers' green demands and LSPs' perception of these demands. As Table 5 indicates, the shippers seem to give their green demands a higher score than the LSPs, which interestingly makes this gap the only one of the 
five green gaps where the shippers' mean values are higher than those of the LSPs'. However, most of the category gaps are relatively small, indicating that LSPs and shippers agree to a large extent. Nonetheless, the categories of fuel, eco-driving and energy data indicate that there are gaps between what the shippers demand and how the LSPs perceive these demands. The confidence intervals for these categories do overlap to some extent (see Appendix A).

Table 5 - Mean values representing Gap 4

\begin{tabular}{|c|c|c|c|}
\hline & $\begin{array}{c}\text { Shippers' stated } \\
\text { demand (B) }\end{array}$ & $\begin{array}{l}\text { LSPs' perception } \\
\text { of demand }(C)\end{array}$ & Gap 4 \\
\hline Fuel & 3,50 & 2,84 & 0,66 \\
\hline Emission data & 3,30 & 3,00 & 0,30 \\
\hline Energy data & 3,06 & 2,51 & 0,54 \\
\hline Transport planning & 3,03 & 2,71 & 0,31 \\
\hline Logistics system design & 3,08 & 3,02 & 0,06 \\
\hline Environmental & & & \\
\hline Management Systems & 3,50 & 3,21 & 0,29 \\
\hline Eco driving & 3,23 & 2,67 & 0,56 \\
\hline Choice of partners & 3,05 & 2,72 & 0,34 \\
\hline
\end{tabular}

\section{Gap 5}

Gap 5 represents the internal gap between shippers' stated green demands and their perception of the green offers from the LSPs. The results in Table 6 indicate that the stated demands and the perceived offers match very well. For some green categories the gap is more or less non-existent, which is the case for choice of partners, environmental management systems, environmentally classified vehicles, emissions data, fuel and energy data. Small gaps appear for the remaining categories, and in all those cases the shippers' perception of the offers is higher than their stated demands. Thus, the shippers appear to perceive that the LSPs offer more than what they themselves demand. According to the confidence intervals (Figure A5, Appendix A), there seems to be a small tendency towards a larger spread for the perceptions of the offers, than for the stated demands amongst the shippers. 
Table 6 - Mean values representing Gap 5

$\begin{array}{rccc}\text { Fuel } & \begin{array}{c}\text { Shippers' stated } \\ \text { demand (B) }\end{array} & \begin{array}{c}\text { Shippers' perception } \\ \text { of offer (D) }\end{array} & \text { Gap 5 } \\ \text { Environmentally classified } & 3,50 & 3,59 & 0,09 \\ \text { vehicles } & 3,86 & 3,93 & 0,07 \\ \text { Emission data } & 3,30 & 3,22 & -0,08 \\ \text { Energy data } & 3,06 & 2,94 & -0,12 \\ \text { Combination of transport } & & 3,06 & 0,19 \\ \text { Transport planning } & 3,03 & 3,29 & 0,26 \\ \text { Logistics system design } & 3,08 & 3,42 & 0,33 \\ \text { Environmental } & & & -0,03 \\ \text { Management Systems } & 3,50 & 3,47 & 0,30 \\ \text { Eco driving } & 3,23 & 3,53 & 0,00 \\ \text { Choice of partners } & 3,05 & 3,06 & \text { Totally disagree } \rightarrow 5=\text { Fully agree }\end{array}$

\section{Discussion and further research needs}

This paper has presented the development of a gap model that is of relevance for the green interface between LSPs' green offers and shippers' green demands. Furthermore, the developed gap model has been applied to this green interface. In this section we discuss the identified gaps, as well as the usability of the gap model in this specific context. We end the section with an elaboration on potential improvements to the developed model. Based on our experience of applying the model, we highlight categories of importance in the future use of the model.

\section{Identified gaps}

Wandel et al. (1992) suggest that supply and demand on the logistics market should preferably match, but the findings from this paper indicate this is not the case for the green logistics market. As described earlier in this paper, the study involves five different gaps, all of which deal with the LSP-shipper interface. Three of these gaps are external (both LSPs' and shippers' views are included) and two are internal (either LSPs' or shippers' views are included), and interestingly the two internal gaps represent both the largest and the smallest gaps. Gap 2, where LSPs give their views on their own offers and their perception of demands, is the largest gap, whereas Gap 5, where shippers give their view on their own demands and the LSPs' offers, represents the 
smallest. Moreover, a comparison between the five different gaps shows that Gaps 1,2 and 3 are generally the largest ones.

For Gap 1, which focuses on LSPs' stated offers versus shippers' stated demands, the LSPs' stated offers have higher mean values for all green categories than do the shippers' stated demands. This makes Gap 1 a positive gap in accordance with the terminology of Ling and Brooks (1998). If this is in fact the case, it is possible that service quality is too high, as suggested by Large and König (2009), and that LSPs could use resources better elsewhere. Another possible explanation as to why the LSPs' supply of environmental services exceeds the demands of the shippers could be that the LSPs expect green demands to increase in the future and thus want to be prepared. Regardless of the reason, this study indicates that the LSPs overachieve when it comes to their environmental offers.

For Gap 2, where LSPs are asked about their own green offers and their perception of shippers' green demands, the gaps are even larger than for Gap 1 (Lings and Brooks, 1998). As previously mentioned, Gap 1 shows over-achievement and Gap 2 deepens the understanding indicating that LSPs seem to be aware of the fact that they overachieve. Moreover, LSPs seem to think that they are further ahead of shippers. The fact that LSPs both seem to be aware of their overachievement and perceive the gap in the interface as rather large, supports the suggestion that LSPs want to be prepared for future environmental demands. However, a discussion of the reason for the gaps is beyond the scope of this paper.

A closer look at Gap 3, which examines LSPs' stated offers versus the shippers' perception of those offers, reveals that shippers do not share the same perception of green supply as LSPs. For all green categories the shippers' responses result in lower mean values than those of the LSPs'. This could mean one of two things: first, it is possible that the LSPs offer more than the shippers are aware of; if this is the case, Gap 3 could show that the LSPs fail to communicate their environmental offers on the green logistics market. Second, Gap 3 could indicate that the shippers have different views and different levels of maturity when it comes to the green categories. Thus, although communication between the two actors might be clear, the shippers and the LSPs do not fully understand one another. Again, it is not possible to get a full explanation for Gap 3 from the survey used in this study. 
Gap 4, which asks both LSPs and shippers for their views of demand in the interface between the two types of actors, the shippers' demands exceed the LSPs' perception of the demands. This is interesting, as this gap is the only one where the shippers have higher mean values than the LSPs, and it is thus the only negative gap (Lings and Brooks, 1998) of the five studied. However, compared to Gap 3, the gaps are relatively small for most of the green categories. This could indicate that shippers are more successful in communicating their green demands than the LSPs are in communicating their green offers. On the other hand, it could also suggest that LSPs underestimate the shippers' green demands, and that shippers are in fact not good enough at communicating their demands.

The final gap studied is Gap 5, which shows the shippers' views on both green supply and green demand. The lack of gaps suggests that shippers are pleased with the offers from the LSPs since their demands are met. Interestingly, the shippers do not seem to see the big gaps between the green offers and green demands that the LSPs seem to perceive in Gaps 1 and 2. Thus, the shippers do not seem to perceive the possible over-achievement that the LSPs describe. As suggested earlier, one explanation for this could be that there is a lack in the communication between the LSPs and the shippers when it comes to environmental offers.

Wolf and Seuring (2010) suggest that LSPs' green supply exceeds the shippers' green demands and, although this is a conclusion that is not related to the different green categories of this study, this suggestion supports the general findings presented in this paper.

\section{Perceptions of the categories studied}

This study suggests that there are several gaps on the green logistics market. However, the gaps identified can be the result of how the respondents' perceived the categories studied. For each of the gaps discussed above, it is possible that LSPs and shippers have different perceptions of the categories and therefore have different points of reference. It is also possible that respondents within the same actor group (LSP or shipper) have different perceptions of the green categories. The survey responses, and therefore the mean values too, are naturally dependent on these perceptions. The confidence intervals illustrated in Appendix A can provide some guidance in this matter as they indicate that the same actor group seems to share approximately the same understanding of the categories. Some very small tendencies towards variations (longer confidence intervals) is, however, notable in Gap 1, suggesting that LSPs have a more similar 
view of their stated offers, as compared to the shippers' view of their stated demands. In Gap 2 a similar small tendency can be identified, suggesting that LSPs have more similar views of their stated demands as compared to how they perceive the shippers' demands. Future research is needed to confirm if these tendencies actually exist, and to bring clarity as to why these differences may occur.

\section{Applying the gap model to new areas}

In this paper we have developed and applied a gap model for the interface on the green logistics market. This is an interface that, as far as we know, the gap model has not been applied to previously. As stated in the literature, one of the strengths of this model is that new categories can be added. We have also shown that new categories cannot only be added, but fully exchanged to suit new areas where they could be of interest to identify, study and create better awareness and understanding of gaps between actors. Most studies apply gap studies to address service quality on the interface between one buying and one selling company. However, we see potential for gap analyses to be further used to study differences in perceptions among other actors (for example: internal company departments, or as a complement to bench-marking studies). We believe there is an interesting future for gap analyses, with an increased use outside the traditional areas of service quality. The gap model developed and used for the purpose of this paper has given a more detailed picture of the green logistics market than has previously been available. The model adds to the findings of Wolf and Seuring (2010), who do not specify how LSPs are ahead of shippers on the green logistics market. Use of the model can provide a better insight, both into were the largest differences can be found, and detailed knowledge regarding the nature of internal and external gaps.

\section{Potential improvements and future use of the developed gap model}

However, the gap model shows some potential for improvement. First, although it enables a description of the green logistics market, the gap model may not give a complete picture of this market. For example, it is possible that there are other green categories that could also be of relevance and that the use of different categories would result in different findings from those discussed here. Secondly, the gap model merely suggests to what extent the green categories are taken into account in the green logistics market and illustrates this with the five different gaps. The gap model does not provide suggestions as to why the gaps occur. To gain an understanding 
about why the gaps occur, further research is needed. In accordance with Yin (2009), case studies could be one possible approach for such research, since they have the potential to answer the why-questions. Thirdly, the two wrongly phrased categories, mentioned earlier in the paper should have been caught earlier on in the research process. However, even though these categories were taken out of the data set for the involved question, they do not seem to have affected the overall results of the study.

Improvements could also have been made for the data collection of the survey material. For example, a survey sent by regular mail instead of via e-mail would have provided better knowledge about who had answered the survey and who had not, and would thus offer a better understanding of whom to remind in order to increase the response rate. Moreover, the survey study used as input to the gap model merely provides answers from actors on the Swedish market. If the survey had been sent out to additional countries, answers from these would perhaps differ from the Swedish results. On the other hand, there is also a possibility of similar results from the other countries and they would probably have supported the findings from this Swedish survey. An interesting path for further research would therefore be to conduct similar studies in other countries to learn if the situation on the green logistics market is the same for those countries as for Sweden.

Even considering the limitations of both the gap model and the data collection, the results of the survey seem to show a relatively clear picture of the green logistics market. Taking the above improvement possibilities into account, the gap model could prove useful in studies of other green interfaces, such as those between shippers and the receivers of goods.

The green service offer is a relatively new addition to the regular offer of LSPs, and one might wonder who has been part of the development of this new offer. LSPs know the logistics business, while shippers have outsourced their logistics to the LSPs. So, who is best suited to decide which green categories to include in an offer? Perhaps collaboration between the two actors is needed for them both to better understand and adapt to each other. Again, additional research on the green logistics market is called for. 


\section{Conclusions}

In this paper we have developed and applied a gap model for the study of the green logistics market. In doing so, we have shown that there is a potentially rich area of research for the successful use of gap models; we have also gained new and more detailed insight into the gaps on the green logistics market. Our findings indicate that there are several internal and external gaps on this market. Interestingly the two internal gaps represent both the largest and smallest gaps; the largest gap addresses the LSPs' view of their offers and how they perceive the demand from the shippers (Gap 2). This gap indicates that the LSPs perceive themselves to be ahead of market requirements. A gap also occurs when the shippers' own demands are compared to the LSPs' stated offers (Gap 1). It could be argued that this overachievement may be a way for LSPs to take control of the market development, or that they want to be prepared for increased environmental demands. As a worst case scenario, this overachievement is service overkill and a waste of resources.

A third large gap between the stated offers of the LSPs and the shippers' perception of the offers (Gap 3) indicates that even if the LSPs are aware of their overachievements, the shippers are not. This gap could be a problem if the LSPs overachieve in order to take control and steer the green market development. If that is the case, one could point out the urgent need for improved information exchanges and collaboration between the actors.

The smallest gap identified (Gap 5) indicates that the shippers' demands are satisfied. This gap also indicates that there is no need for communication in order to make today's customers more satisfied, since they do not ask for more. Instead communication can be needed to foster and shape future demands.

Before taking action or providing any recommendations on how to act in this matter, there is a need to deepen the understanding regarding the reason why these gaps occur. Furthermore, we have identified potential areas for the future development of the gap model, suggesting more studies applying similar tools. 


\section{Acknowledgements}

We want to acknowledge and thank the Swedish Governmental Agency for Innovation Systems, VINNOVA, for their financial support of this research.

\section{Appendix A}

Confidence intervals for the five different gaps are shown in the figures below.

Take in Figure A1

Take in Figure A2

Take in Figure A3

Take in Figure A4

Take in Figure A5

\section{References}

Armstrong, J. S. \& Overton, T. S. (1977), "Estimating Nonresponse Bias in Mail Surveys", Journal of Marketing Research (JMR), Vol. 14, No. 3, pp. 396-402.

Aronsson, H. \& Huge-Brodin, M. (2006), "The Environmental Impact of Changing Logistics Structures", International Journal of Logistics Management, Vol. 17, No. 3, pp. 394-415.

Björklund, M. 2005. Purchasing Practices of Environmentally Preferable Transport Services Guidance to Increased Shipper Considerations. Doctoral Thesis Lund University.

Bommer, M., O'Neil, B. \& Treat, S. (2001), "Strategic Assessment of the Supply Chain Interface: a Beverage Industry Case Study", International Journal of Physical Distribution \& Logistics Management, Vol. 31, No. 1, pp. 11.

Bowersox, D., J. \& Closs, D., L. (1996), Logistical Management: The Integrated Supply Chain Process, McGraw-Hill, New York.

Chen, C. (2001), "Design for the Environment: A Quality-Based Model for Green Product Development", Management Science, Vol. 47, No. 2, pp. 250-263.

Coley, F. J. S. \& Lemon, M. (2009), "Exploring the design and perceived benefit of sustainable solutions: a review", Journal of Engineering Design, Vol. 20, No. 6, pp. 543-554.

Coyle, J., J., Bardi, E., J. \& Novack, R., A. (2000), Transportation (5th edition), South-Western College Publishing, Ohio.

CSCMP. (2010), "Supply Chain Management - Terms and Glossary", available at: http://cscmp.org/digital/glossary/glossary.asp (accessed 21 June 2010).

de Haas, H. \& Kronborg Jensen, J. (2010), "Green Transportation - Does the Customer Care?", in: Stentoft Arlbjørn, J., (Ed.), The 22nd Annual NOFOMA Conference - June 10-11, 2010 - Kolding, Denmark - Logistics and Supply Chain Management in a Globalised Economy, University of Southern Denmark, pp. 1049-1064. 
Djurfeldt, G., Larsson, R. \& Stjärnhagen, O. (2010), Statistisk verktygslåda 1: Samhällsvetenskaplig Orsaksanalys med Kvantitativa Metoder, Studentlitteratur AB, Lund.

Edvardsson, B. (1997), "Quality in New Service Development: Key Concepts and a Frame of Reference", International Journal of Production Economics, Vol. 52, No. 1/2, pp. 31-46.

EEA 2007. Transport and Environment: on the way to a new transport policy, TERM 2006: indicators tracking transport and Environment in the European Union.

Enarsson, L. (1998), "Evaluation of Suppliers: How to Consider the Environment", International Journal of Physical Distribution \& Logistics Management, Vol. 28, No. 1, pp. 5.

Fabbe-Costes, N., Jahre, M. \& Roussat, C. (2009), "Supply Chain Integration: the Role of Logistics Service Providers", International Journal of Productivity and Performance Management, Vol. 58, No. 1, pp. 71-91.

Facanha, C. \& Horvath, A. (2005), "Environmental Assessment of Logistics Outsourcing", Journal of Management in Engineering, Vol. 21, No. 1, pp. 27-37.

Forslund, H. (2006), "Performance Gaps in the Dyadic Order Fulfillment Process", International Journal of Physical Distribution \& Logistics Management, Vol. 36, No. 8, pp. 580-595.

Forslund, H. (2010), "Supply Chain Performance Management: Logisitcs Service Providers' Perspective", in: Stentoft Arlbjørn, J., (Ed.), The 22nd Annual NOFOMA Conference Logistics and Supply Chain Management in a Globalised Economy, University of southern Denmark, pp. 341-356.

Giannakis, M. (2007), "Performance Measurement of Supplier Relationships", Supply Chain Management, Vol. 12, No. 6, pp. 400-411.

Hakatie, A. \& Ryynänen, T. (2007), "Managing Creativity: A Gap Analysis Approach to Identifying Challenges for Industrial Design Consultancy Services", Design Issues, Vol. 23, No. 1, pp. 28-46.

Hopkins, S. A., Strasser, S., Hopkins, W. E. \& Foster, J. R. (1993), "Service Quality Gaps in the Transportation Industry: An Empirical Investigation", Journal of Business Logistics, Vol. 14, No. 1, pp. 145-161.

Jensen, A. (2007) "Designing Intermodal Transport Systems: A Conceptual and Methodological Framework", Konings, R., Priemus, H. \& Nijkamp, P. (eds.), The future of intermodal freight transport - Operations, design and implementation, Edward Edgar Publishing, Cheltenham, pp. 187-205.

Knemeyer, A. M. \& Murphy, P. R. (2005), "Is the Glass Half Full or Half Empty?", International Journal of Physical Distribution \& Logistics Management, Vol. 35, No. 10, pp. 708-727.

Kumar, R. \& Kumar, U. (2004), "A Conceptual Framework for the Development of a Service Delivery Strategy for Industrial Systems and Products", Journal of Business \& Industrial Marketing, Vol. 19, No. 5, pp. 310-319.

Lambert, D. M. \& Cooper, M. C. (2000), "Issues in Supply Chain Management", Industrial Marketing Management, Vol. 29, No. 1, pp. 65-83.

Lambert, D. M. \& Harrington, T. C. (1990), "Measuring Nonresponse Bias in Customer Service Mail Surveys", Journal of Business Logistics, Vol. 11, No. 2, pp. 5-25.

Lammgård, C. 2007. Environmental Perspectives on Marketing of Freight Transports - The Intermodal Road-Rail Case. Doctoral Thesis, Göteborg University. 
Large, R. O. \& König, T. (2009), "A Gap Model of Purchasing's Internal Service Quality: Concept, Case Study and Internal Survey", Journal of Purchasing \& Supply Management, Vol. 15, No. 1, pp. 24-32.

Lemoine, O. W. \& Skjoett-Larsen, T. (2004), "Reconfiguration of Supply Chains and Implications for Transport: A Danish Study", International Journal of Physical Distribution \& Logistics Management, Vol. 34, No. 10, pp. 793-810.

Lin, C. \& Ho, Y. (2008), "An Empirical Study on Logistics Service Providers' Intention to Adopt Green Innovations", Journal of technology management \& innovation, Vol. 3, No. 1, pp. 17-26.

Lings, I. N. \& Brooks, R. F. (1998), "Implementing and Measuring the Effectiveness of Internal Marketing", Journal of Marketing Management, Vol. 14, No. 4/5, pp. 325-351.

Lundgren, K. 2001. Mått för Transport - på Lokal Nivå. Publikation 2001:8. Kristianstad, Sverige.

Martinsen, U. \& Huge-Brodin, M. (2010), "Greening the offerings of logistics service providers", in: Stentoft Arlbjørn, J., (Ed.), The 22nd Annual NOFOMA Conference Logistics and Supply Chain Management in a Globalised Economy, pp. 969-984.

Maxwell, D., Sheate, W. \& van der Vorst, R. (2006), "Functional and Systems Aspects of the Sustainable Product and Service Development Approach for Industry", Journal of Cleaner Production, Vol. 14, No. 17, pp. 1466-1479.

McKinnon, A. C. (2003) "Logistics and the Environment", Hensher, D. A. \& Button, K. J. (eds.), Handbook of Transport and the Environment, Elsevier, Amsterdam, pp. 665-685.

McKinnon, A. C. (2008), "The Potential of Economic Incentives to Reduce CO2 Emissions from Goods Transport", Paper presented at The 1st International Transport Forum on 'Transport and Energy: the Challenge of Climate Change', 28-30 May, Leipzig, available at http://www.internationaltransportforum.org/Topics/Workshops/WS3McKinnon.pdf (accessed 25 May 2011).

McKinnon, A. C. \& Piecyk, M. I. (2009), "Measurement of CO2 Emissions from Road Freight Transport: A Review of UK Experience", Energy Policy, Vol. 37, No. 10, pp. 3733-3742.

Mukherjee, A. \& Nath, P. (2005), "An Empirical Assessment of Comparative Approaches to Service Quality Measurement", Journal of Services Marketing, Vol. 19, No. 3, pp. 174184.

Parasuraman, A., Zeithaml, V. A. \& Berry, L. L. (1985), "A Conceptual Model of Service Quality and Its Implications for Future Research", Journal of Marketing, Vol. 49, No. 4, pp. 41-50.

Pujari, D., Wright, G. \& Peattie, K. (2003), "Green and Competitive: Influences on Environmental New Product Development Performance", Journal of Business Research, Vol. 56, No. 8, pp. 657-671.

Roth, A. \& Kåberger, T. (2002), "Making Transport Systems Sustainable", Journal of Cleaner Production, Vol. 10, No. 4, pp. 361-371.

Seth, N., Deshmukh, S. G. \& Vrat, P. (2006), "A Conceptual Model for Quality of Service in the Supply Chain", International Journal of Physical Distribution \& Logistics Management, Vol. 36, No. 7, pp. 547-575.

Sheffi, Y. (1986), "Carrier/Shipper Interactions in the Transportation Market: An Analytical Framework", Journal of Business Logistics, Vol. 7, No. 1, pp. 1-27.

Shostack, G. L. (1977), "Breaking Free from Product Marketing", Journal of Marketing, Vol. 41, No. 2, pp. 73-80. 
Skjoett-Larsen, T., Thernoe, C. \& Andersen, C. (2003), "Supply Chain Collaboration", International Journal of Physical Distribution \& Logistics Management, Vol. 33, No. 6, pp. 531-549.

Skålén, P. \& Fougère, M. (2007), "Be(com)ing Normal - Not Excellent", Journal of Organizational Change Management, Vol. 20, No. 1, pp. 109-125.

Spens, K. M. \& Bask, A. H. (2002), "Developing a Framework for Supply Chain Management", International Journal of Logistics Management, Vol. 13, No. 1, pp. 73-88.

Stefansson, G. (2006), "Collaborative Logistics Management and the Role of Third-Party Service Providers", International Journal of Physical Distribution \& Logistics Management, Vol. 36, No. 2, pp. 76-92.

Stock, J. R. \& Lambert, D. M. (1992), "Becoming a "World Class" Company With Logistics Service Quality", International Journal of Logistics Management, Vol. 3, No. 1, pp. 7381.

Wandel, S., Ruijgrok, C. \& Nemoto, T. (1992) "Relationships Among Shifts in Logistics, Transport, Traffic and Informatics - Driving Forces, Barriers, External Effects and Policy Options", Storhagen, N. G. \& Huge-Brodin, M. (eds.), Logistiska Framsteg - Nordiska Forskningsperspektiv på Logistik och Materialadministration, Studentlitteratur, Lund, pp. 96-136.

Wolf, C. \& Seuring, S. (2010), "Environmental Impacts as Buying Criteria for Third Party Logistical Services", International Journal of Physical Distribution \& Logistics Management, Vol. 40, No. 1, pp. 84-102.

Wu, H.-J. \& Dunn, S. C. (1995), "Environmentally Responsible Logistics Systems", International Journal of Physical Distribution \& Logistics Management, Vol. 25, No. 2, pp. 20-38.

Yin, R. (2009), Case Study Research: Design and Methods, Sage Publications, London.

Zeithaml, V. A., Parasuraman, A. \& Berry, L. L. (1985), "Problems and Strategies in Services Marketing", Journal of Marketing, Vol. 49, No. 2, pp. 33-46. 